\title{
Elevated temperature, strain rate jump microcompression of nanocrystalline nickel
}

Gaurav Mohanty ${ }^{\mathrm{a} *}$, Jeffrey M. Wheeler ${ }^{\mathrm{a}}$, Rejin Raghavan ${ }^{\mathrm{a}}$, Juri Wehrs ${ }^{\mathrm{a}}$, , , Madoka Hasegawa $^{\mathrm{a}}$, Stefano Mischler ${ }^{\mathrm{b}}$, Laetitia Philippe ${ }^{\mathrm{a}}$ and Johann Michler ${ }^{\mathrm{a}}$

5

${ }^{a}$ EMPA-Swiss Federal Laboratories for Materials Science and Technology, Laboratory for Mechanics of Materials and Nanostructures, Feuerwerkerstrasse 39, CH-3602 Thun, Switzerland; ${ }^{\mathrm{b}}$ Tribology and Interface Chemistry Group, Materials Institute, Ecole Polytechnique Fédérale de Lausanne (EPFL), Station 12, CH-1015 Lausanne, Switzerland

\section{Supplementary data}

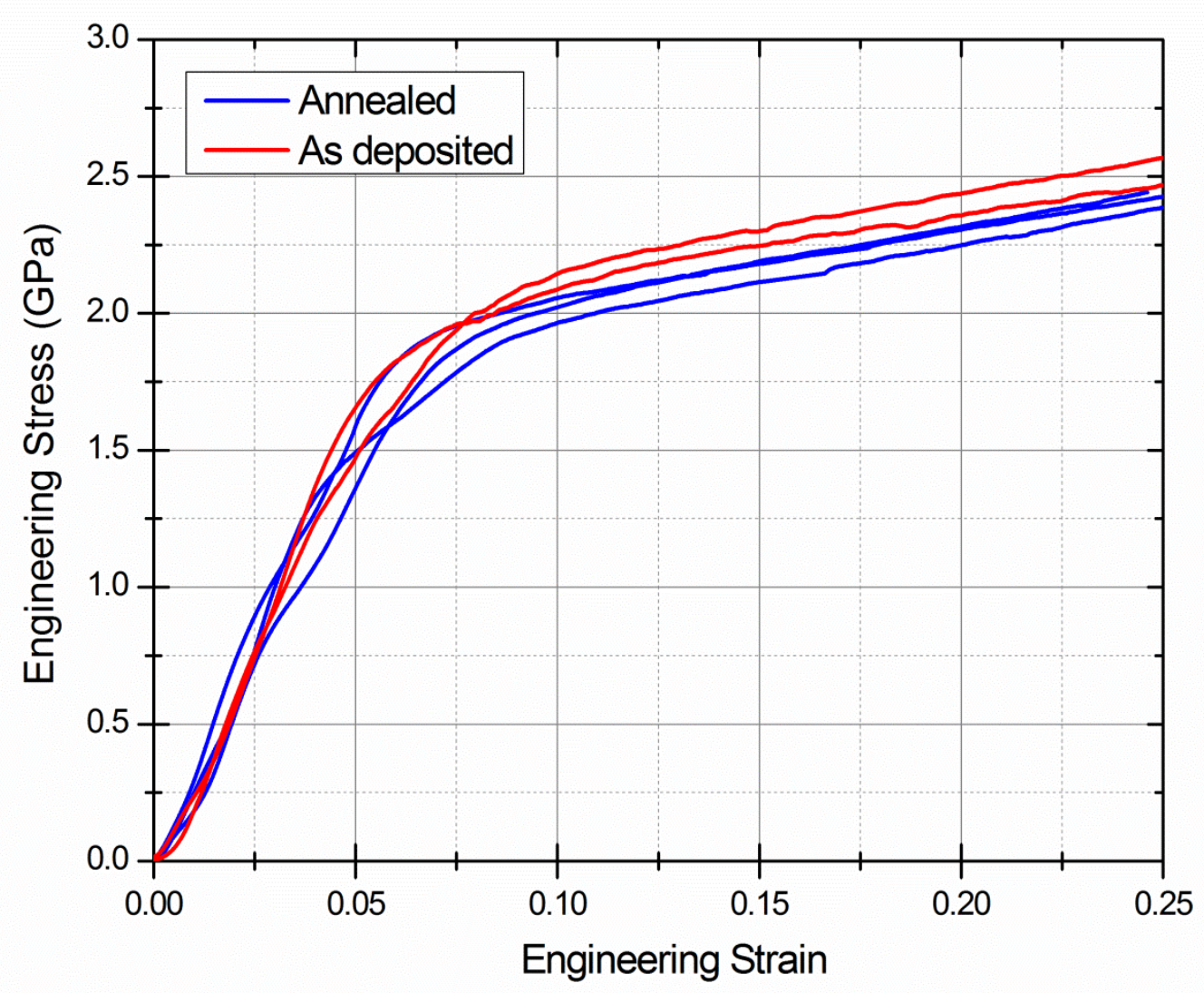

Figure 1S. Engineering stress-strain curves for room temperature microcompression of asdeposited and annealed (tested at $100{ }^{\circ} \mathrm{C}$ previously) nanocrystalline nickel film shows no noticeable change in mechanical properties. 